\title{
A Perspective on Computer Programming Education for Children in China
}

\author{
Yizhe $\operatorname{Sun}^{1}, \mathrm{Chu} \mathrm{Luo}^{2, *}$ \\ ${ }^{1}$ College of Engineering and Computing \\ The University of South Carolina, Columbia, SC 29208, USA \\ ${ }^{2}$ School of Information Technology and Engineering \\ Guangzhou College of Commerce, Guangzhou City, Guangdong, China \\ Corresponding author: Email: yizhes@email.sc.edu
}

\begin{abstract}
Computer programming education for children is currently a roaring industry in China. For the cultivation of children's logical thinking ability and innovation ability, the government and investors have been making diverse efforts to develop the industry. Yet, there is more room to improve for efficient advancement of this industry. Hence, in this paper, we provide a detailed summary and several insights of the youth programming education in China, through open data and the experience of a practitioner. We found imbalances and differences regarding such an industry across regions in China. We also revealed the operation patterns of this industry.
\end{abstract}

Keywords: education, programming, children

\section{INTRODUCTION}

Unlike professional programming education, computer programming education for children focuses on the cultivation of logical thinking ability and innovation ability. This concept originated in western countries such as the United States since 2000s. However, there was little popularity established in China until the recent decade.

Driven by new types of educational innovations in China, the youth programming industry emerged in the end of 2013. Relying on the strong growth in demand, children's programming is currently attracting rapidly increasing investment and able to serve millions of Chinese children under 18 . In recent three years, the market size of China's children's programming exceeded tens of billions yuan, according to data provided by ifenxi.com [1] (a consultancy of technological business).

To illustrate the characteristics and opportunities of this industry, in this paper we offer a detailed summary and several insights of the youth programming education in China, through open data and the experience of a practitioner (i.e., the first author). We found imbalances and differences regarding such an industry across regions in China. We also revealed the operation patterns of this industry. This paper can potentially benefit various readers, including education policymakers/investors/practitioners, students/parents, as well as researchers in this field.

\section{METHODOLOGY}

We conducted the data search within open sources, including Baidu Index services [2] (i.e., search counts of a keyword per day on the Baidu search engine), the Chinese Central Government's official web portal, and several companies' official websites. All collected data is valid by the date of writing (May 26, 2021).

Because the first author had recent work experience in such an industry, we aim to, briefly, demonstrate the market via multiple aspects, including the national momentum, industrial operations and authors' personal insights.

Data visualization of Baidu Index is provided by Baidu's open services. Other data is visualized on Office software by authors. 


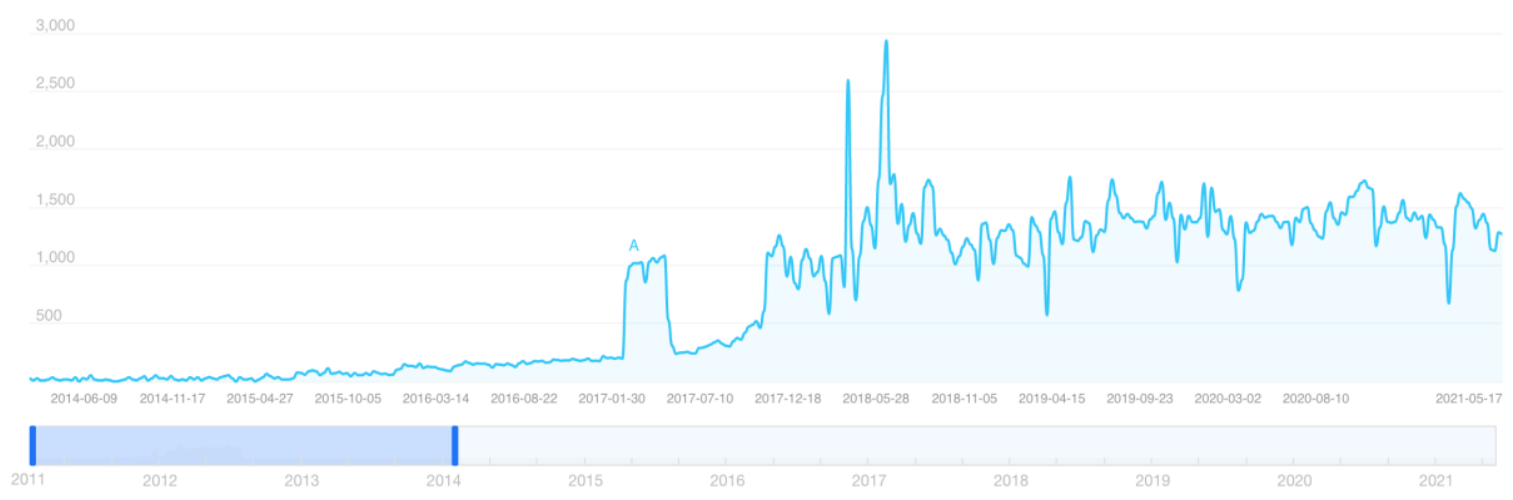

Figure 1 Search count per day of the keyword "youth programming" provided by Baidu Index.

\section{RESULTS}

\subsection{National Momentum}

From 2014 to 2021, the Baidu Search Index for the keyword "youth programming" reflected a growing trend (Fig. 1). In 2017, the Chinese State Council issued the "Development Plan on the New Generation of Artificial Intelligence", which clearly pointed out that the gradual promotion of programming education in primary and secondary schools is a boost for China's programming education industry. This released a signal that the country will vigorously promote youth programming education. In the same year, universities and middle schools across the country increased their inclination to programming education.

Especially, 17 of "985 Plan" colleges and universities gave extra credits for science and technology students. "211 Plan" colleges and universities followed closely, while programming was gradually incorporated into the K12 teaching system.

Therefore, at the beginning of 2017, the Baidu Index also ushered in the first significant increase. In May 2018, it reached the highest daily search volume of nearly 3,000 . In November of the same year, it stabilized at an average daily search volume of around 1,500. With the introduction of national policies, elementary and middle schools in some areas have incorporated programming into their main subjects. And in 2018, Beijing, Nanjing, Guangzhou, and Tianjin will include programming in the scope of special recruitment for the high school entrance examination.

Fig. 2 shows the search count of youth programming on Baidu since the beginning of 2014. In coastal areas such as Guangdong, Zhejiang, Jiangsu, the search rate for youth programming is much higher than other areas. Since the end of 2013, China has set off a wave of STEAM education. This kind of interdisciplinary education originated in the $\mathrm{K} 12$ education field in the United States. Now it has driven the development of
China's education. With the emergence of the Scratch modular programming language during the same period, graphical programming teaching products began to appear.

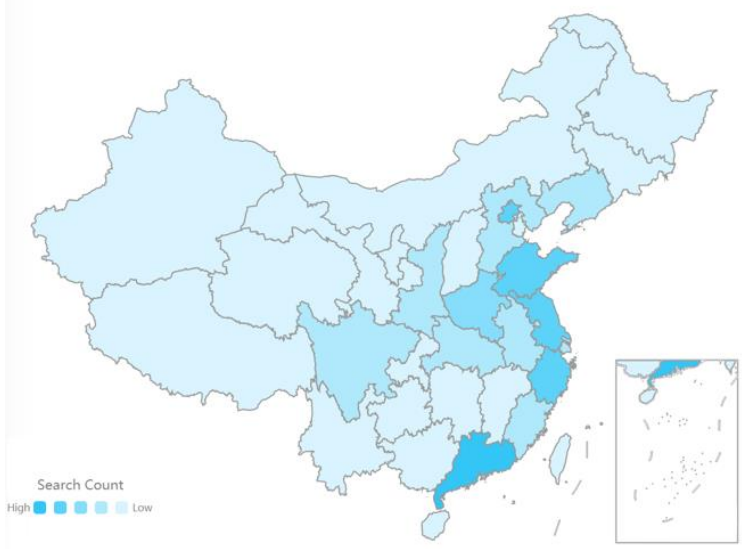

Figure 2 Search count distribution across China regarding the keyword "youth programming" provided by Baidu Index.

While traditional programming and robot education have also completed the transformation, from pure mechanical control to the combination of graphical programming and robots. It is also due to the rapid popularization and development of some domestic children's programming leading companies in the local area after financial activities in 2017. For example, after Codemao obtained 3 billion investment in Shenzhen, it vigorously popularized youth programming in Shenzhen, and gradually expanded such education.

Moreover, the importance of education has prompted an increase in expenditure. Since 2013, per capita consumption expenditure has been in a constantly growing trend (Fig. 3). The growth rate has remained at about $7.5 \%$. At the same time, the proportion of expenditure on education, culture and entertainment remained at about $11.5 \%$. Given the current national policy, education in the future will become one of the factors that stimulate the country's domestic demand. 


\section{3-2020 Per Capita Consumption Expenditure and} Expenditure on Education, Entertainment and Culture

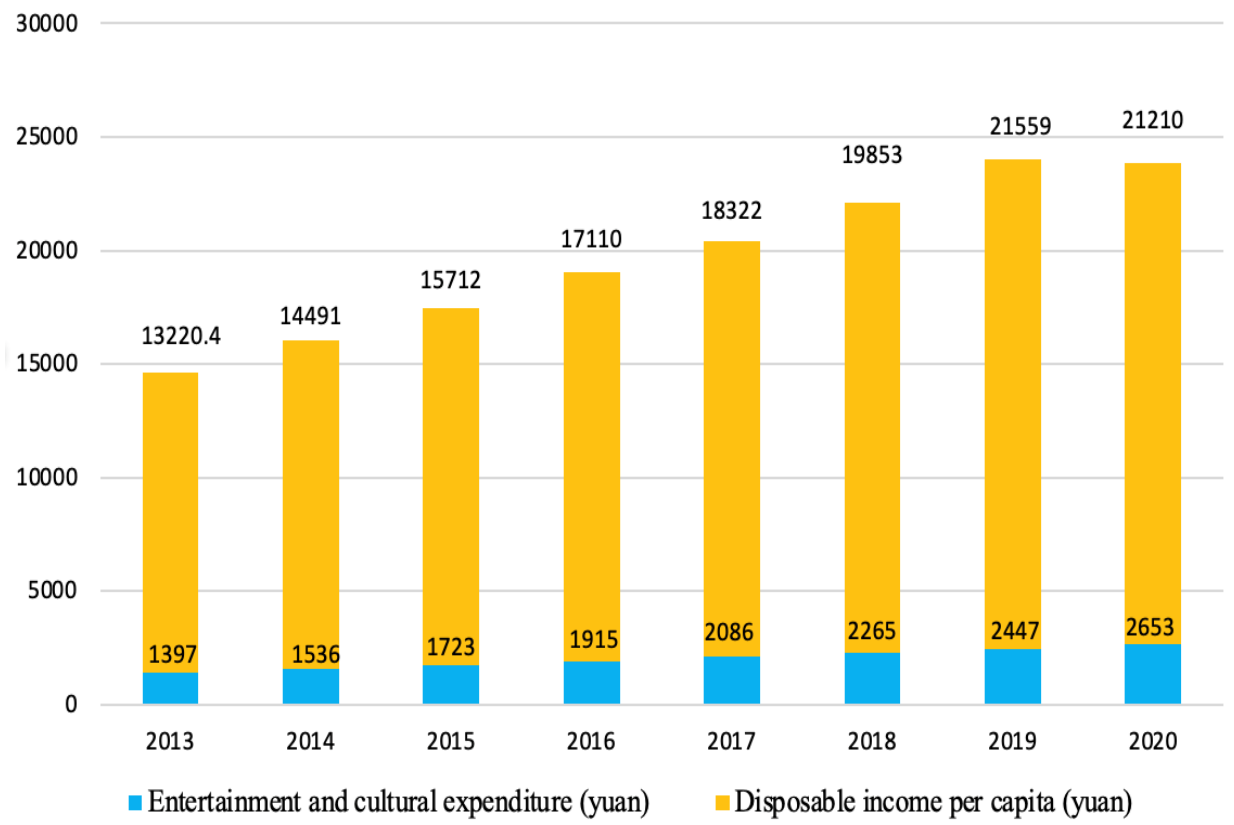

Figure 3 2013-2020 per capita consumption expenditure in China.

As the concept of education continues to penetrate the hearts of the younger generation, especially through their parents, the share of education investment will continue to rise. Early education and quality education will usher in a "blowout" development.

Companies in the children's education industry also received explosive investment in 2017. The number of investment projects and the amount of investment have repeatedly climbed to new highs. In 2020, due to the impact of the epidemic of COVID-19, both per capita consumption expenditure and per capita disposable income have fallen slightly, by a decrease of $1.6 \%$ yearon-year.

\subsection{Industrial Operations}

Fig. 4 shows several domestic programming education industry leaders. The teaching \& learning mode of the entire industry is also led by these education companies. These companies also have channels connected with capital markets to increase the quality and scale.

\begin{tabular}{|l|l|l|l|l|}
\hline Company & \multicolumn{1}{|c|}{ Feature } & Target Age & \multicolumn{1}{c|}{ Learning Mode } & \multicolumn{1}{c|}{ Courses } \\
\hline WitProgram & $\begin{array}{l}\text { Multi-stage } \\
\text { Courses }\end{array}$ & $7-15$ & $\begin{array}{l}\text { Online teaching }+ \\
\text { Offline clubs }\end{array}$ & $\begin{array}{l}\text { Knowledge, Thinking, Works } \\
\text { development }\end{array}$ \\
\hline CodePKU & $\begin{array}{l}\text { Based on game } \\
\text { design }\end{array}$ & $7-18$ & $\begin{array}{l}\text { Online teaching + } \\
\text { Offline elite projects }\end{array}$ & $\begin{array}{l}\text { Scratch for beginners, } \\
\text { Java and C afterwards }\end{array}$ \\
\hline Xigua City & $\begin{array}{l}\text { AI tutor }+ \\
\text { Human tutor }\end{array}$ & $6-12$ & Online teaching & $\begin{array}{l}\text { Project development, } \\
\text { Game development }\end{array}$ \\
\hline Hetaol01 & $\begin{array}{l}\text { AI tutor }+ \\
\text { Human tutor }\end{array}$ & $6-12$ & $\begin{array}{l}\text { Online teaching }+ \\
\text { Offline competition }\end{array}$ & $\begin{array}{l}\text { Learning in educational } \\
\text { video games }\end{array}$ \\
\hline Xiaomawang & $\begin{array}{l}\text { Multi-stage } \\
\text { Courses }\end{array}$ & $6-17$ & $\begin{array}{l}\text { Online teaching }+ \\
\text { Offline teaching }\end{array}$ & $\begin{array}{l}\text { Scratch for beginners, } \\
\text { C++ and Python afterwards }\end{array}$ \\
\hline Codemao & $\begin{array}{l}\text { AI tutor }+ \\
\text { Human tutor }\end{array}$ & $4-16$ & $\begin{array}{l}\text { Online teaching + } \\
\text { Offline competition }\end{array}$ & $\begin{array}{l}\text { Kitten, 3D graphics, Python, } \\
\text { Nemo editor, Animation for } \\
\text { young children }\end{array}$ \\
\hline
\end{tabular}

Figure 4 Several domestic programming education industry leaders. 
The teaching \& learning mode of all companies is almost similar: online + offline teaching. Online teaching involves human + AI dual teacher. The average age group targeted is 6-16 years old, with similar corresponding courses for each age.

As the most common course content, Scratch is a software developed by Massachusetts Institute of Technology specifically for 9-11 years old. The Scratch graphical programming language is also the most popular in this industry. For children over the age of 11, almost all children start to learn $\mathrm{C}++$ or Python.

The most special company is Codemao, which has the record of the highest single investment for programming education in China. Codemao has developed Kitten, the country's first self-developed graphical programming language. This achievement makes Codemao take the lead in both programming teaching and research. Compared with other companies, the educational philosophy of Codemao is more suitable for young children. It is worth mentioning that Codemao's Nemo (i.e., a programming editor) can also perform programming education on mobile devices and practice on mobile phones. In other words, what Codemao does is to integrate programming perfectly into children's life.

As shown in Fig. 5, the entire industry is composed of programming entities, business and customers. The main body of the industry includes the main programming languages such as Scratch, Kitten, Python, $\mathrm{C}++$ and so on. Relevant courses are mainly for customers to learn according to different age groups. The main method of teaching research and development is to introduce foreign and domestic talents for teaching and research. And the teaching staff are supposed to cooperate with universities to transport relevant talents, and to tap potential teachers within the enterprise.

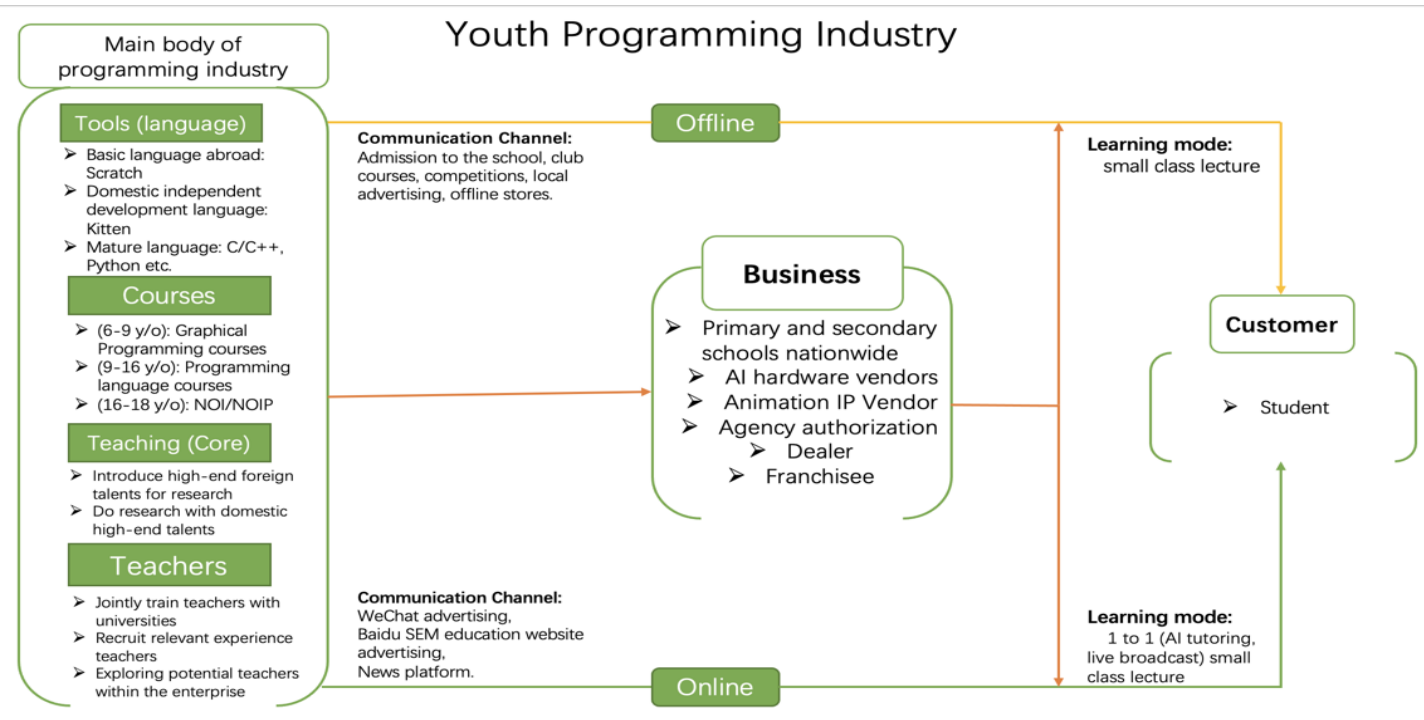

Figure 5 The structure of youth programming industry.

For marketing purposes, the industry needs to expand the popularity via proper communication channels which connect the educational companies and potential customers. Sending posts on WeChat or advertising on Baidu is common. In addition, local news platforms may also be effective for parents and students to gain information about educational companies.

The offline channel of communication can let parents know youth programming through school promotion and club activities. Offline uses a relatively traditional teaching model. In the entire industry, the coordinated development of business and customers ensures the steady progress of the entire industry.

As an intermediary between customers and the main body of the industry, business has been continuously popularizing youth programming education across the country in many aspects, such as collaboration with schools, providing hardware/software educational tools, assessing companies, developing solutions for franchisee and so on.

\section{DISCUSSION}

In this section, we aim to provide several insights based on the collected data and the experience of a practitioner.

At present, the situation in the industry looks very promising. However, the outstanding domestic companies that we analyzed are all located in coastal cities. What really needs our attention is the youth education in northwestern cities. Compared with the activity in the southern capital market, education companies in the northwest have limited investment (nearly no at all). The income sources of these companies are mostly through self-sufficiency, that is, from their sales. 
Some companies have expanded the penetration rate of programming education through local promotion, school club activities, and related competitions. In fact, among these places in the northwest, parents' cognition of programming as a children activity is highly backward. Most parents still believe that programming has nothing to do with the knowledge that children are exposed to. Therefore, if these companies want to expand the influence of children's programming in the northwest, it is quite difficult. Perhaps, the government and schools can provide more support for parents to understand youth programming education.

Despite the size of these companies, capable teachers are rare. For children, the benefit of having a good teacher is significant: guidance in competitions for children's future advancement, the way of thinking in programming, and so on. To train capable teachers, the universities may instruct more students about this industry.

Another challenge in this industry is the lack of facilities. Both the form and content of the courses can be improved. Witnessing the success of Codemao, we suggest that educational companies should invest more resources to develop more software tools for education. Perhaps, open-source tools can be created for children's education of computer programming. On open-source platforms, all developers can contribute to implement certain features for pedagogical innovations, such as content about a new programming concept (e.g., [3]), new interactive learning interface (e.g., [4] and [5]), and new AI tutor technology (e.g., [6], [7] and [8]).

\section{CONCLUSION}

Computer programming education for children is currently a flourishing industry in China. For the cultivation of children's logical thinking ability and innovation ability, the government and investors have been making various efforts to develop the industry. Yet, there can still be potential ways of efficient advancement of this industry. In this paper, we provided a detailed summary and several insights of the youth programming education in China, through open data and the experience of a practitioner. We found imbalances and differences regarding such an industry across regions in China. We also revealed the operation patterns of this industry. This paper can potentially inspire multiple groups of readers, including education policy-makers/practitioners, students/parents, as well as researchers in this field.

\section{AUTHORS' CONTRIBUTIONS}

The authors contributed equally in this paper.

\section{ACKNOWLEDGMENTS}

We would like to thank reviewers and editors for their constructive advice.

\section{REFERENCES}

[1] ifenxi. https://www.ifenxi.com/.

[2] Baidu Index.

https://index.baidu.com/v2/index.html\#/.

[3] C. F. Botella, A. Peñalver, M. Quesada-Martínez, F. Bermejo, and F. Borrás, "Teaching the sequential programming concept using a robotic arm in an interactive museum," ACM International Conference on Human Computer Interaction (Interacción '19), 2019.

[4] T. Mattis, "Concept-aware Live Programming: Integrating Topic Models for Program Comprehension into Live Programming Environments", ACM International Conference on the Art, Science and Engineering of Programming (Programming '17), 2017.

[5] E. Lotfi, and B. Mohammed, "Teaching Object Oriented Programming Concepts Through a Mobile Serious Game", ACM International Conference on Smart City Applications (SCA '18), 2018.

[6] M. Wang, W. Wu, and Y. Liang, "A Novel Intelligent Tutoring System For Learning Programming," International Conference on Development and Application Systems (DAS), pp. 162-168, 2020.

[7] D. Hooshyar, R. B. Ahmad, M. Fathi, M. Yousefi, and M. Hooshyar, "Flowchart-based Bayesian Intelligent Tutoring System for computer programming," International Conference on Smart Sensors and Application (ICSSA), pp. 150-154, 2015.

[8] C. J. Butz, S. Hua, and R. B. Maguire, "A WebBased Intelligent Tutoring System for Computer Programming," IEEE/WIC/ACM International Conference on Web Intelligence (WI'04), pp. 159$165,2004$. 